\title{
Incomplete ossificatie van de humeruscondylen (IOHC) bij de hond
}

\author{
I. Gielen, Y. Samoy, B. Van Ryssen \\ Vakgroep Medische Beeldvorming van de Huisdieren en Orthopedie van de Kleine Huisdieren, \\ Faculteit Diergeneeskunde, Universiteit Gent, Salisburylaan 133, B-9820, Merelbeke.
}

ingrid.gielen@ugent.be

\section{AMENVATTING}

Incomplete ossificatie van de humeruscondylen (IOHC) bij de hond is een vrij zeldzaam elleboogprobleem dat voornamelijk bij spaniëlrassen wordt gezien maar ook bij andere rassen kan voorkomen. Deze aandoening gaat niet altijd gepaard met klinische symptomen maar kan de aanleiding zijn van elleboogkreupelheid en zelfs condylaire humerusfracturen. De diagnose van IOHC is niet altijd eenvoudig. Radiografisch is de fissuur niet altijd zichtbaar. Computertomografie is de meest efficiënte beeldvormingstechniek om deze aandoening met zekerheid te diagnosticeren. Indien het dier geen klachten vertoont, kan conservatieve therapie worden overwogen maar in geval van kreupelheid is het plaatsen van een compressieschroef de meest gangbare behandeling.

\section{INLEIDING}

In de praktijk komen elleboogproblemen vaak voor, meestal bij opgroeiende honden van grote en reuzenrassen (Cook, 2001; Scott en Witte, 2011). Er zijn verscheidene aandoeningen die kreupelheid in de elleboog kunnen veroorzaken, waaronder een reeks traumatische letsels, zoals fracturen en luxaties (McKee et al., 2005; Sajik et al., 2016), degeneratieve letsels, zoals flexor enthesiopathie (De Bakker et al., 2013), "medial compartment syndrome" (Coppieters et al., 2015), artrose en een reeks congenitale en ontwikkelingsstoornissen, zoals elleboogdysplasie. Elleboogdysplasie is de verzamelnaam voor vier aandoeningen: osteochondrose van de mediale humeruscondyl, losse processus anconeus (LPA), elleboogincongruentie en losse processus coronoïdeus (LPC). In de recente literatuur worden afwijkingen van de processus coronoïdeus "medial coronoid disease" (MCD) genoemd en als de voornaamste oorzaak van elleboogkreupelheid aanzien (Samoy et al., 2006; VillamonteChevalier et al., 2015).

Een meer zeldzame elleboogaandoening is incomplete ossificatie van de humeruscondylen (IOHC), waarbij er door het niet-fusioneren van de laterale en mediale humeruscondyl een fissuur of barst tussen de twee condylen blijft bestaan. De distale humerus ontstaat uit een fusie van drie ossificatiecentra: een groter mediaal en een lateraal centrum en een kleiner centraal centrum dat deel uitmaakt van de mediale humeruscondyl. De fissuurlijn is gelokaliseerd ter hoogte van de kraakbeengrens tussen de laterale en de mediale humeruscondyl, waarvan de fusie normaal op een leeftijd van acht à twaalf weken plaatsgrijpt (Moores, 2006). De kraakbeenplaat die tussen beide ossificatiecentra aanwezig is, loopt maar tot aan de groeiplaat van de distale humerus, terwijl de fissuur die men kan aantonen bij IOHC soms tot aan het foramen supratrochleare loopt. Dit foramen bevindt zich proximaal van de distale groeiplaat. Vermoedelijk loopt de fissuur verder door stressfracturen die ontstaan door reeds bestaande zwakheid van de humerus (Butterworth en Innes, 2001; Moores, 2006). Er is ook beschreven dat IOHC ontstaat ten gevolge van stressfracturen. Rondom de fissuurlijn is er sclerotisch beenweefsel aanwezig. Dit komt typisch voor bij stressfracturen en ondersteunt deze hypothese (Moores et al., 2012).

\section{SIGNALEMENT}

IOHC wordt vaker aangetroffen bij de spaniëlrassen, zoals de Engelse springer-spaniël en de cockerspaniël, waarbij de aanleg erfelijk zou zijn (Marcellin-Little et al., 1994; Moores, et al., 2012). Deze aandoening komt ook voor bij de labrador-retriever, de rottweiler en ook bij andere, minder typische rassen (Moores, 2006; Favril et al., 2014). IOHC komt vaak bilateraal voor en meer bij reuen dan bij teven (Denny, 1983; Marcellin-Little et al., 1994; Moores, 2006). De dieren zijn meestal van middelbare leeftijd (Denny, 1983; Marcellin-Little et al., 1994; Butterworth and Innes, 2001) met een normaal lichaamsgewicht. 

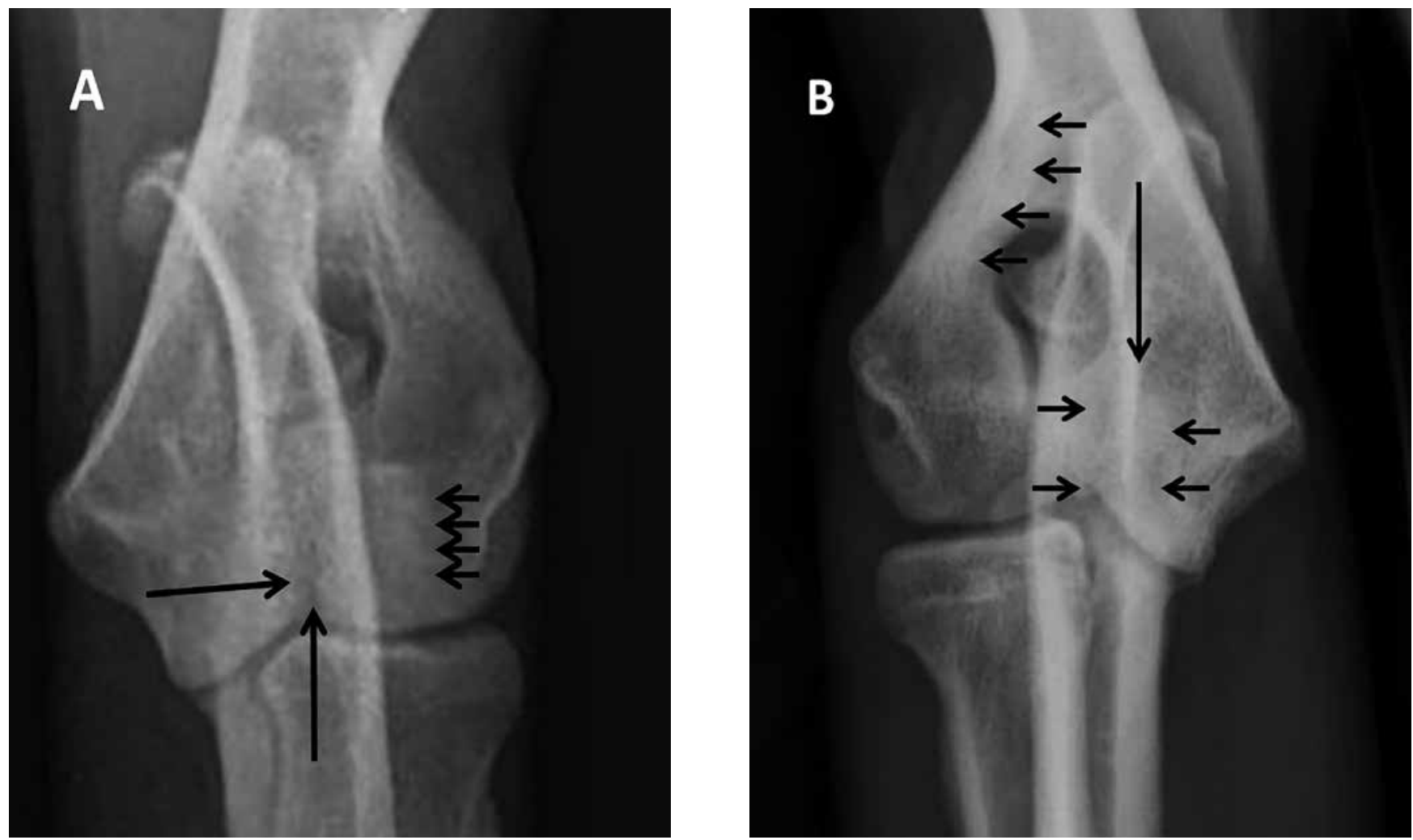

Figuur 1. Voor-achterwaartse opname van ellebogen: A. Doorheen de ulna is een fissuur zichtbaar die ongeveer halverwege tot aan het foramen supratrochleare reikt (grote pijlen). Rond de fissuur is er sclerose aanwezig (kleine pijltjes). B. Doorheen de ulna is vaag een fissuur waar te nemen bij deze vizsla (grote pijl). Rond de fissuur en ter hoogte van de laterale humerus zuil is er sclerose aanwezig (kleine pijltjes).

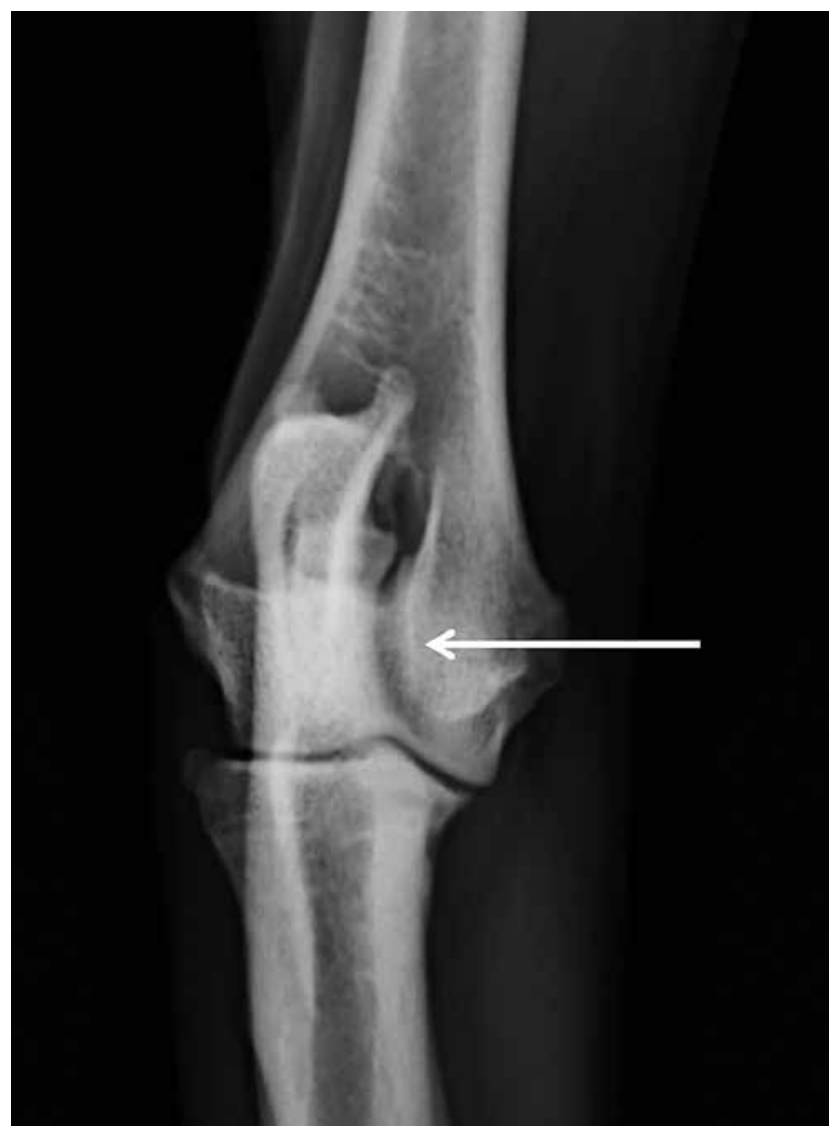

Figuur 2. Voor-achterwaartse opname van een elleboog waar een duidelijke mach-lijn te zien is (witte pijl). Deze mag niet verward worden met een fissuur die bij IOHC kan opgemerkt worden.

\section{SYMPTOMEN}

Incomplete ossificatie van de humeruscondyl kan ernstige pijn en kreupelheid veroorzaken. Als gevolg hiervan kunnen problemen ontstaan bij het trainen van werkhonden (Moores, 2006; Fitzpatrick, et al., 2009). Vaak breidt deze fissuur zich uit tot aan het foramen supratrochleare net proximaal van de groeiplaat, waarschijnlijk ten gevolge van een stressfractuur (Moores, 2006). Deze fissuur blijft een zwakke plek in de distale humerus en kan leiden tot een spontane fractuur, zelfs na een normale activiteit of na een gering trauma, zoals ergens afspringen. Het resultaat kan een eenvoudige fractuur zijn zoals een fractuur van de laterale condyl of een meer ingewikkelde zoals een bicondylaire fractuur (Fitzpatrick et al., 2009).

IOHC kan soms als een toevalsbevinding worden aangetroffen. In dat geval vertonen de honden geen symptomen.

\section{DIAGNOSE}

Om zeker te zijn van de diagnose van IOHC moet de intercondylaire fissuur zichtbaar zijn. Dit is op röntgenfoto's niet altijd het geval vanwege de inherente superpositie van de botstructuren. Op voorachterwaartse radiografieën van uitstekende kwaliteit kan soms de fissuur zichtbaar zijn maar dan moet de röntgenbundel exact parallel lopen met de fissuurlijn. Daarom zijn meestal meerdere voor-achterwaartse 
opnamen onder verschillende hoeken noodzakelijk. Deze worden niet routinematig uitgevoerd omdat de symptomen in veel gevallen niet altijd duidelijk zijn en deze aandoening niet overwogen wordt. De fissuurlijn kan partieel of compleet zijn, helemaal tot aan het foramen supratrochleare (Figuur 1). Het is belangrijk om een fissuurlijn ten gevolge van IOHC niet te verwarren met een mach-lijn (Figuur 2), een radiolucente lijn ter hoogte van de distale condylen die gecreëerd wordt door superpositie van twee botstructuren en die eigenlijk gezichtsbedrog is. Soms is er nieuwbeenvorming of een periostale reactie zichtbaar ter hoogte van de laterale zijde van de epicondyl en/of sclerose rond het foramen supratrochleare (Hoskinson en Tucker 2001; Cook en Cook, 2009) (Figuur 3).

Als er een vermoeden is van IOHC en indien het klinisch en radiografisch onderzoek geen uitsluitsel geeft, kan scintigrafie nuttig zijn om de lokalisatie in het ellebooggewricht te bevestigen. De contralaterale kant, die dikwijls ook aangetast is, kan tegelijkertijd onderzocht worden (Debruyn et al., 2013) (Figuur 4).

Computertomografie (CT) is de ideale techniek om een fissuur aan te tonen omdat superpositie van overliggende structuren vermeden wordt (De Rycke et al., 2002; Carrera et al., 2008). De fissuurlijn doorheen de distale humerus is duidelijk zichtbaar op de transversale beelden (Moores, 2006). Ze manifesteert zich als een translucente lijn met onregelmatige, sclerotische randen (Figuur 5 en 6). Er wordt aangeraden om de contralaterale kant ook te controleren vermits deze aandoening heel dikwijls bilateraal aanwezig is. Dikwijls worden ook elleboogincongruentie, afwijkingen van het coronoïd en artrose samen met IOHC in hetzelfde gewricht waargenomen (Carrera et al., 2008). Op CT-studies kunnen tevens andere elleboogproblemen aangetoond worden, zoals MCD, LPA en elleboogincongruentie. Ook artrose is duidelijk zichtbaar op CT en komt vaak voor bij ellebogen met IOH. De meest voorkomende lokalisatie van nieuwbeenvorming is de laterale zijde van de epicondyl. Bij uitgebreide artrose is nieuwbeenvoming aanwezig op de laterale en de mediale epicondyl (Carrera et al., 2008).

Bij aangetaste dieren kan elleboogartroscopie ook helpen bij de diagnose. In de meeste gevallen wordt een barst of fissuur in het gewrichtskraakbeen waargenomen op de overgang tussen de laterale en mediale humeruscondyl (Meyer-Lindenberg et al., 2002) (Figuur 7).

\section{BEHANDELING}

De behandeling van IOHC blijft controversieel. Conservatieve behandeling geeft meestal geen goed resultaat en resulteert op lange termijn meestal in een complete condylaire fractuur. Toch wordt meestal geen chirurgische behandeling aangeraden als er geen symptomen zijn en de diagnose enkel als toevalsbevinding wordt gesteld (Favril et al., 2014).
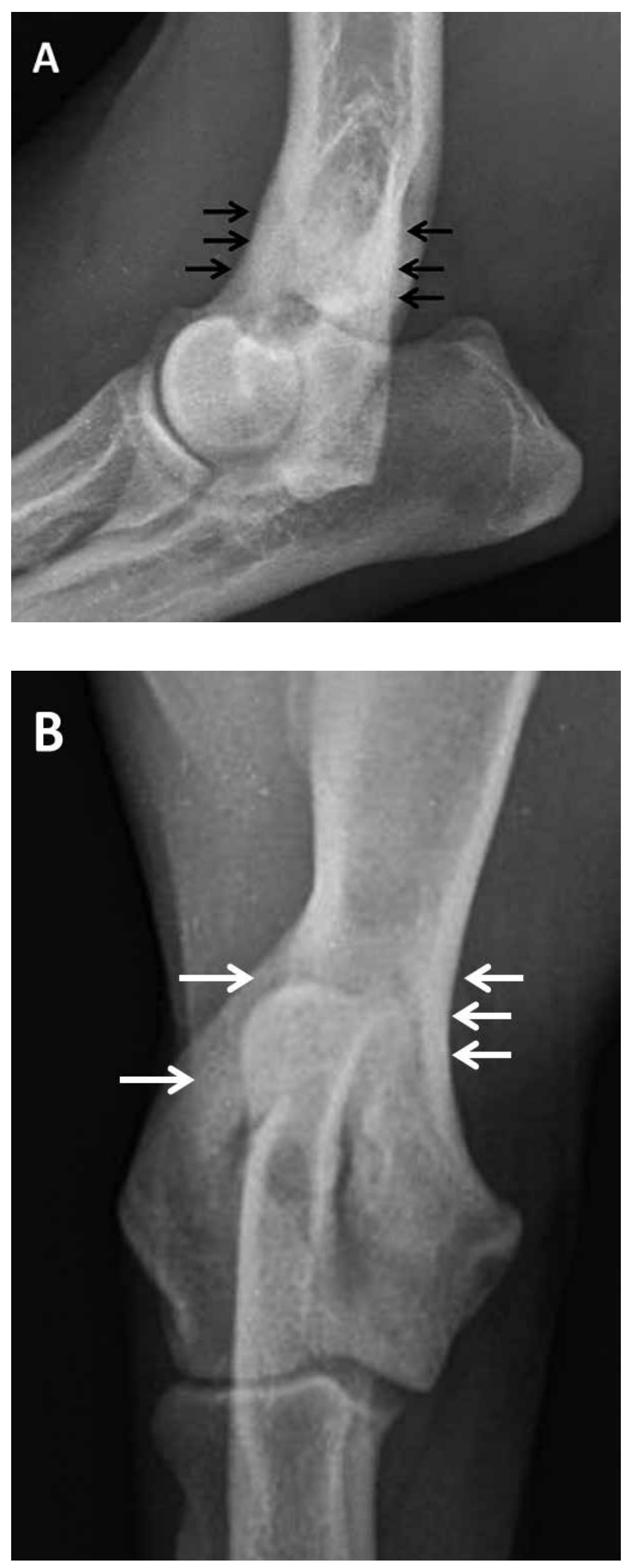

Figuur 3. A. Medio-laterale en B. voor-achterwaartse radiografieën van de rechterelleboog van een mannelijke, Engelse springerspaniël van zes maanden oud met IOHC en wisselende kreupelheid. A. Op de laterale opname ter hoogte van de distale humerus proximaal van het foramen intertrochleare is uitgesproken sclerose aanwezig (pijltjes). B. Op de voor-achterwaartse opname is de fissuurlijn amper te zien maar valt de erge sclerose rond het foramen intertrochleare op (pijltjes). 


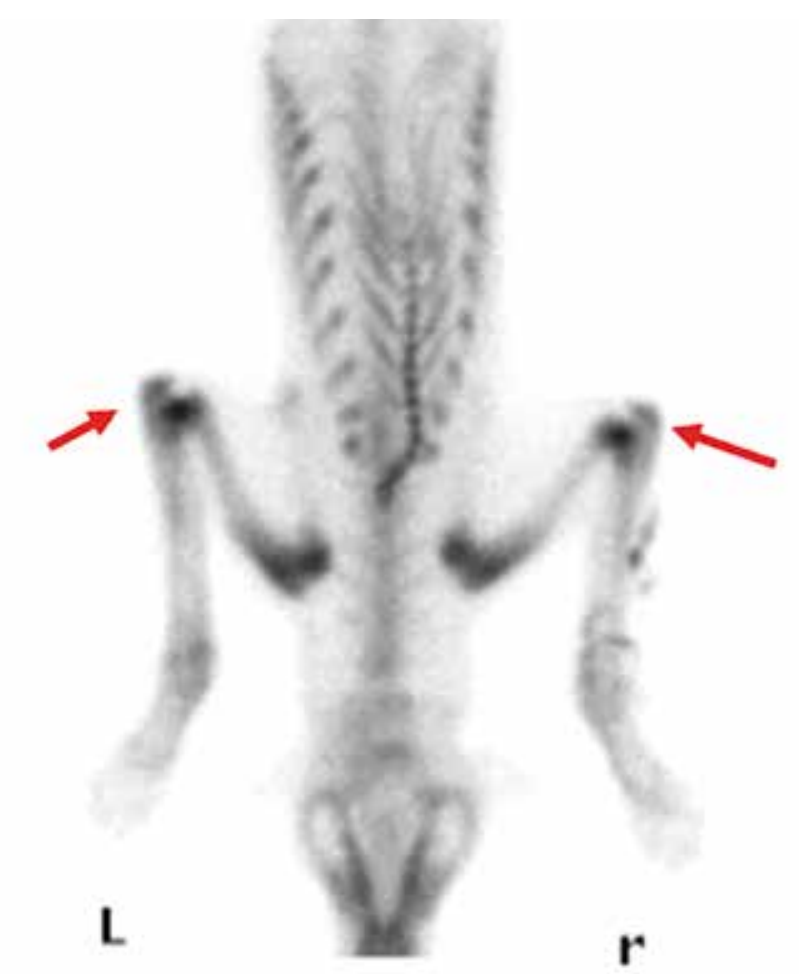

Figuur 4. Scintigrafisch onderzoek uitgevoerd bij een hond met bilaterale IOHC. In beide ellebogen is er een verhoogde opname van de radioactieve tracer (rode pijlen).

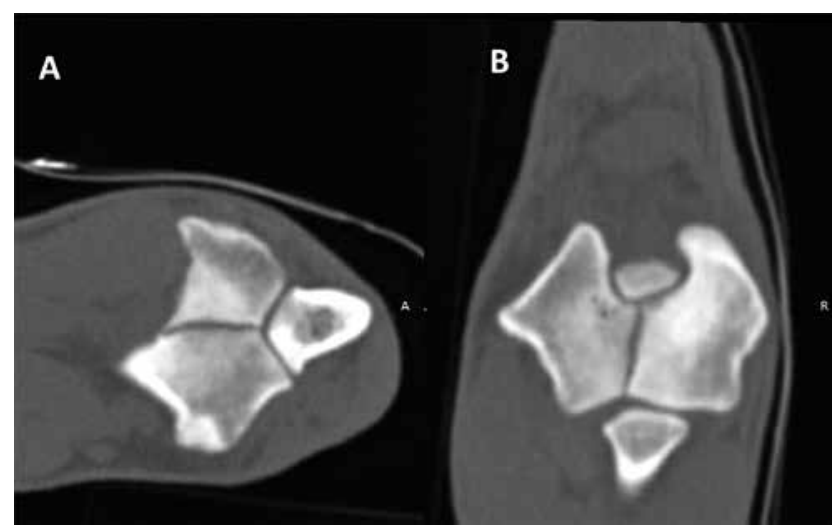

Figuur 5. A. Transversale en B. dorsale reconstructie. CT-beelden in botvenster van een rechterelleboog van een hond met IOHC. De fissuurlijn doorheen de distale humerus is duidelijk zichtbaar op de beelden. Ze manifesteert zich als een translucente lijn omgeven met onregelmatige, sclerotische randen.

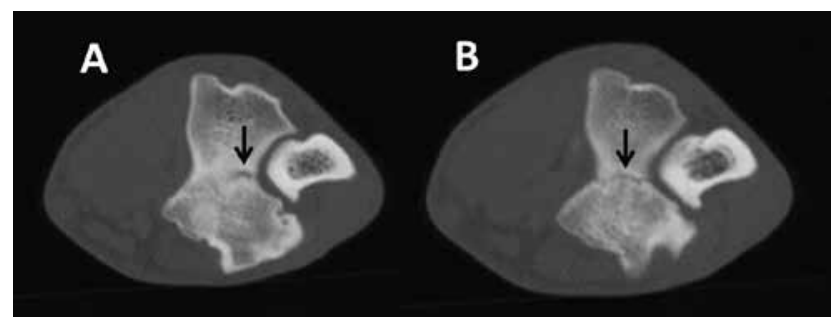

Figuur 6. A. Transversale CT-beelden in botvenster ter hoogte van de distale humerus en $B$. meer distaal van een acht maanden oude vizla (cf. Figuur 1B). De fissuur (zwarte pijlen) kan een zeer discreet voorkomen hebben. Op het linkerbeeld is er sclerose rondom de fissuur.
In gevallen van pijn en kreupelheid is chirurgie wel aangewezen om de symptomen op te lossen en om preventief een complete fractuur te voorkomen.

De meest gekozen chirurgische behandeling is het plaatsen van een compressieschroef doorheen de twee condylen om het letsel te stabiliseren en de regio te versterken (Figuur 8). Een andere behandelingsmethode is het plaatsen van botenten in het defect. Er is echter nooit bewezen dat de resultaten hiervan beter zouden zijn dan bij de traditionele compressieschroef. Vaak blijft na behandeling van IOHC of van IOHC-geassocieerde fracturen de fissuur bestaan. Dit zou veroorzaakt kunnen worden door abnormale botheling. Door de aanwezigheid van fibreus weefsel of dens trabeculair bot zou de botheling vertraagd of tegengehouden kunnen worden. Aangezien er geen volledige fusie of heling van de fissuurlijn mag verwacht worden, wordt de schroef constant belast, wat op termijn tot metaalmoeheid kan leiden met uiteindelijk het breken van de schroef tot gevolg. Indien dit gebeurt zal de patiënt terug pijn en kreupelheid vertonen (Figuur 9). In het ergste geval kan er zelfs een complete fractuur van de condylen optreden. Deze complicatie kan maanden tot jaren na de ingreep plaatsgrijpen. In dat geval is revisie noodzakelijk om de fractuur te behandelen of om de afgebroken schroef te vervangen (MarcellinLittle, 1994; Moores, 2006; Fitzpatrick et al., 2009).

Laser-enultrageluidbehandeling, eventueel in combinatie met fourage, waarbij gaatjes geboord worden op plaatsen waar bot bloot is komen te liggen met als bedoeling littekenkraakbeen te creëren, zou ook een gunstig effect hebben (Bockstahler et al., 2004).

Toch zijn de afloop en prognose in de meeste gevallen niet zo ongunstig en de meeste honden recupereren zes tot acht weken na de ingreep. Ze hebben dan geen pijn meer, zijn niet kreupel en vertonen een goed functioneel herstel. De meeste patiënten met IOHC ontwikkelen op lange termijn echter milde osteoartrose. De symptomen zijn meestal mild en manifesteren zich door stijfheid na rust (Butterworth en Innes, 2001; Meyer-Lindenberg et al., 2002; Moores, 2006; Fitzpatrick et al., 2009, Favrilet al., 2014).

\section{CONCLUSIE}

Bij honden met elleboogkreupelheid moet incomplete ossificatievan dehumeruscondylenzekeralsdifferentiaaldiagnose worden overwogen. Indien radiografisch onderzoek geen eenduidige diagnose oplevert, is het uitvoeren van een CT-onderzoek zeker het overwegen waard. De prognose na het plaatsen van een compressieschroef is vrij gunstig.

\section{REFERENTIES}

Bockstahler B., Levine D., Millis D. L., Wandrey S. O. N. (2004). In: Egner B. (editor). Essential Facts of Physiotherapy in Dogs and Cats: Rehabilitation and Pain Ma- 


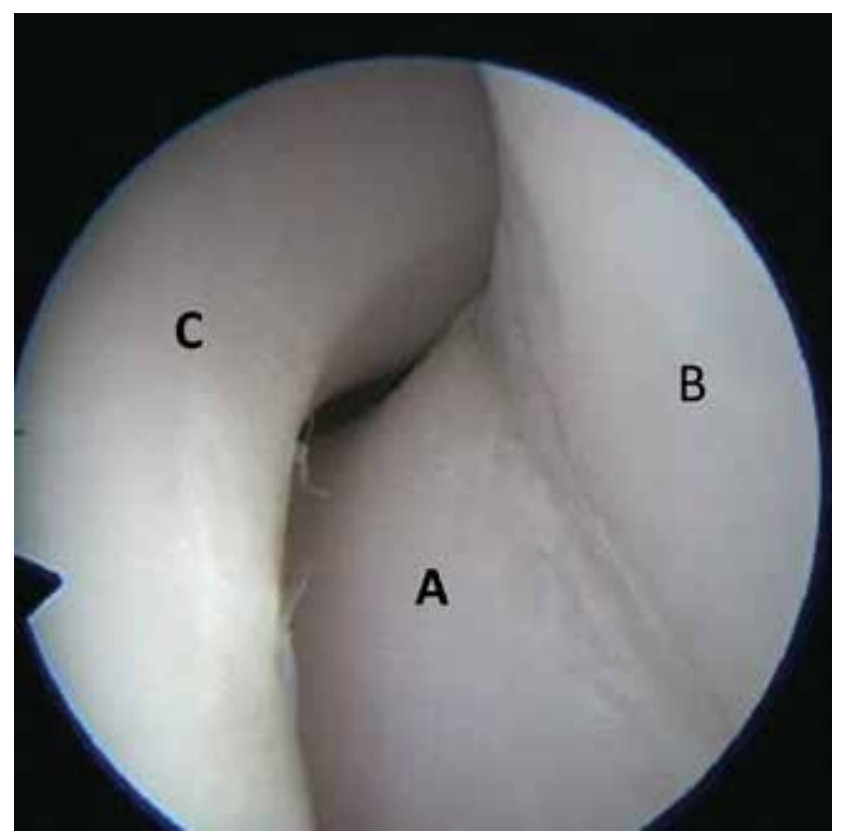

Figuur 7. Artroscopisch beeld van een linkerelleboog met IOHC. Er is een barst of fissuur in het gewrichtskraakbeen ter hoogte van de grens tussen de laterale en mediale humeruscondyl. A. Laterale humeruscondyl, B. mediale humeruscondyl, C. ulna met processus anconeus.

nagement: a Reference Guide with DVD. First edition, BE, Vet Verlag, Babenhausen.

Butterworth S.J., Innes J.F. (2001). Incomplete humeral condylar fractures in the dog. Journal of Small Animal Practice 42, 394-398.

Carrera I., Hammond G.J.C., Sullivan M. (2008). Computed tomographic features of incomplete ossification of the canine humeral condyle. Veterinary Surgery 37, 226-231.

Cook J.L. (2001). Forelimb lameness in the young patient. Veterinary Clinics of North America Small Animal Practice 31, 55-83.

Cook C.R., Cook J.L. (2009). Diagnostic imaging of canine elbow dysplasia: a review. Veterinary Surgery 38, 144-153.

Coppieters E., Gielen I., Verhoeven G., Van Vynckt D., Van Ryssen B. (2015). Erosion of the medial compartment of the canine elbow: occurrence, diagnosis and currently available treatment options. Veterinary and Comparative Orthopaedics and Traumatology 28, 9-18.

de Bakker E., Gielen I., Saunders J.H., Polis I., Vermeire S., Peremans K., Dewulf J., van Bree H., Van Ryssen B. (2013). Primary and concomitant flexor enthesopathy of the canine elbow. Veterinary and Comparative Orthopaedics and Traumatology 26, 1-10.

Debruyn K., Peremans K., Vandermeulen E., Van Ryssen B., Saunders J. (2013). Evaluation of semi-quantitative bone scintigraphy in canine elbows. Veterinary Journal 196, 424-430.

Denny H.R. (1983). Condylar fractures of the humerus in the dog: a review of 133 cases. Journal of Small Animal Practice 24, 185-197.

De Rycke L, Gielen I, van Bree H, Simoens P. (2002). Computed tomography of the elbow joint in clinically normal dogs. American Journal of Veterinary Research 63, 1400-1407.

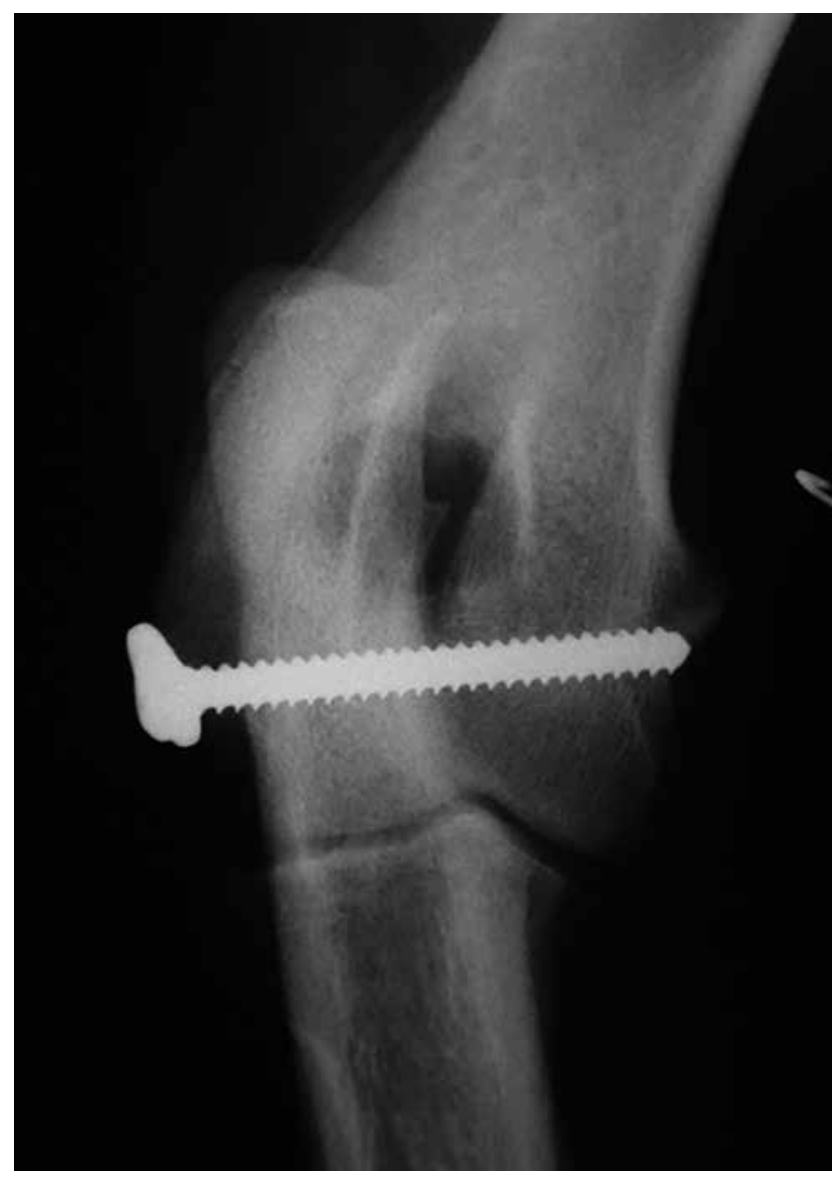

Figuur 8. Een chirurgisch behandelde elleboog met IOHC, waarbij een compressieschroef werd geplaatst.

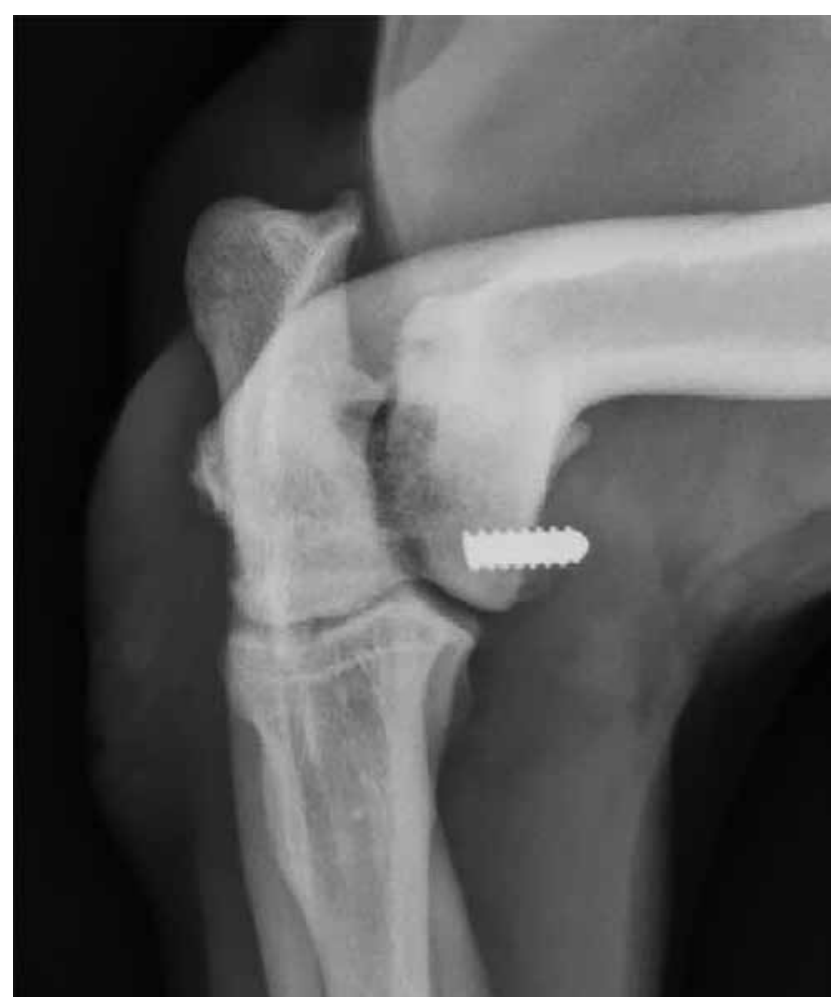

Figuur 9. Een complicatie opgetreden na het plaatsen van een compressieschroef. Door metaalmoeheid is er materiaalbreuk opgetreden. Een deel van de schroef is verwijderd en een resterend deel van de schroef is nog aanwezig. 
Favril S., Van Vynckt D., Gielen I., Van Caelenberg A., Vanderperren K., Van Ryssen B. (2014). Incomplete ossification of the humeral condyle in a young Dogue de Bordeaux. Incomplete ossificatie van de humeruscondyl bij een jonge Bordeaux Dog. Vlaams Diergeneeskundig Tijdschrift 83, 21-27.

Fitzpatrick N., Smith T.J., O’Riordan J., Yeadon R. (2009). Treatment of incomplete ossification of the humeral condyle with autogenous bone grafting techniques. Veterinary Surgery 38, 173-184.

Hoskinson J.J., Tucker R.L. (2001). Diagnostic imaging of lameness in small animals. Veterinary Clinics of North America Small Animal Practice 31, 165-180.

Marcellin-Little D., Deyoung D., Ferries K., Berry C. (1994). Incomplete ossification of the humeral condyle in spaniels. Veterinary Surgery 23, 475-487.

McKee W.M., Macias C., Innes J.F. (2005). Bilateral fixation of Y-T humeral condyle fractures via medial and lateral approaches in 29 dogs. Journal of Small Animal Practice 46, 217-226.

Meyer-Lindenberg A., Heinen V., Fehr M., Nolte I. (2002). Incomplete ossification of the humeral condyle as the cause of lameness in dogs. Veterinary and Comparative Orthopaedics and Traumatology 3, 187-194.

Moores A. (2006). Humeral condylar fractures and in- complete ossification of the humeral condyle in dogs. In Practice 28, 391-397.

Moores A., Agthe P., Schaafsma I. (2012). Prevalence of incomplete ossification of the humeral condyle and other abnormalities of the elbow in English Springer Spaniels. Veterinary and Comparative Orthopaedics and Traumatology 25, 211-216.

Sajik D., Meeson R.L., Kulendra N., Jordan C., James D., Calvo I., Farrell M., Kulendra E. (2016). Multi-centre retrospective study of long-term outcomes following traumatic elbow luxation in 37 dogs. Journal of Small Animal Practice 57, 422-428.

Samoy Y., Van Ryssen B., Gielen I., Walschot N., van Bree H. (2006). Review of the literature: elbow incongruity in the dog. Veterinary and Comparative Orthopaedics and Traumatology 19, 1-8.

Scott H.., Witte P. (2011). Investigation of lameness in dogs. 1. Forelimb. In Practice 33, 20-27.

Villamonte-Chevalier A., van Bree H., Broeckx B., Dingemanse W., Soler M., Van Ryssen B., Gielen I. (2015). Assessment of medial coronoid disease in 180 canine lame elbow joints: a sensitivity and specificity comparison of radiographic, computed tomographic and arthroscopic findings. BMC Veterinay Research 11, 243-251.

De kat is het enige dier dat erin geslaagd is de mens te domesticeren.

\author{
Marcel Mauss (Epinal 1872 - Parijs, 1950) \\ 'Vader' van de Franse antropologie
}

Een hond heeft een baas, een kat heeft bedienden

Je 'hebt' geen kat, je deelt jouw huis met de kat 